\title{
Gestão da Qualidade Total e Qualidade de Vida no Trabalho: o Caso da Gerência de Administração dos Correios
}

\author{
Felipe de Faria Monaco \\ Valeska Nahas Guimarães
}

\section{Resumo}

Este trabalho refere-se aos temas qualidade total e qualidade de vida no trabalho. O objetivo é avaliar as transformações dos aspectos relacionados à qualidade de vida no trabalho, a partir da introdução do programa de qualidade total numa empresa pública prestadora de serviços. É uma pesquisa teórico-empírica de abordagem qualitativa, que privilegiou o estudo de caso. Neste estudo, compreende-se qualidade de vida no trabalho como uma expansão natural da qualidade total, de forma que os programas de qualidade total melhorem os resultados das empresas, mas também a satisfação, o bem-estar e a condição de vida das pessoas.

Palavras-chaves: qualidade total; qualidade de vida no trabalho; relações de trabalho; participação dos funcionários; qualidade de vida.

\section{AbStRACT}

This paper refers to total quality and quality of work life. The main goal is to estimate the changes in the aspects related to quality of work life since the introduction of total quality control. This is a qualitative study based on a theoretic-empirical research. A case study was conducted on a public agency. It is important to say that in this study quality of work life is understood as a natural expansion of total quality because these programs are generally used only as a way to improve the company results. In my concept they should also be seen as a way to improve the people life condition.

Key words: total quality; quality of work life; labor relations; worker's participation; quality of life. 


\section{INTRODUÇĀO}

Este artigo tem por objetivo levar ao conhecimento do público os resultados de um estudo cujo tema vem sendo muito discutido nos meios acadêmicos, assim como no âmbito empresarial. Como ainda está gerando muita polêmica, o assunto apresenta resultados não consensuais, conforme verificado nos estudos de Guimarães (1995) e Vieira (1996), pesquisadores do Núcleo Interdisciplinar de Estudos da Inovação e Trabalho da Universidade Federal de Santa Catarina (NINEIT/ UFSC).

Neste artigo, pretende-se abordar uma dimensão pouco explorada, que enfoca a introdução de programas de qualidade total (PQT) e sua influência na qualidade de vida no trabalho (QVT) na gerência de administração (GERAD) da Empresa Brasileira de Correios e Telégrafos (ECT), uma empresa pública prestadora de serviços. O estudo foi aplicado entre junho e outubro de 1998, quando a empresa, objeto do estudo, se encontrava num processo de reformulação na sua forma de gestão com a implantação do PQT, cujo início data de 1993.

O que se percebe é que muitas empresas adotam o PQT como saída para resolver problemas imediatos e a curto prazo, tais como de relacionamento dentro da empresa, de capacitação de mão-de-obra ou para solucionar problemas de baixa qualidade nos produtos e serviços; entretanto poucas se preocupam realmente com as implicações sociais, culturais e organizacionais de tais programas.

Como se destaca em Lima (1994, p. 64), “até o presente são raras as discussões sobre a legitimidade de tais programas, seu potencial de generalização, possibilidades de concretização de suas propostas e benefícios suscetíveis de serem proporcionados à sociedade como um todo. São igualmente raras as reflexões sobre as origens dessas práticas e a conveniência de sua importação". Outra questão um pouco esquecida na implantação destes programas diz respeito à melhoria da qualidade de vida no trabalho das pessoas, que se entende como fundamental para o sucesso do programa.

Nesse sentido, o presente estudo pretende aprofundar o debate sobre as contribuições do programa de qualidade total para a qualidade de vida no trabalho, tendo como objeto de estudo uma empresa pública de grande porte, que presta serviços de fundamental importância para a sociedade brasileira, e está diretamente relacionada com a melhoria do ambiente de trabalho. A possibilidade oferece também sugestões de modificação no âmbito interno da empresa estudada, contribuindo para o processo de melhoria das condições de trabalho e de vida dos 
empregados. Para tanto, como objetivo geral, buscou-se avaliar as transformações dos aspectos relacionados à QVT a partir da introdução do PQT na Gerência de Administração (GERAD) da Empresa Brasileira de Correios e Telégrafos na sua Diretoria Regional de Santa Catarina (DR/SC).

Para alcançar este objetivo, levantaram-se as etapas e as estratégias de introdução do PQT na empresa; utilizando como referência o Modelo de Walton para aferição de QVT, analisaram-se os aspectos afetados da QVT antes e após a introdução do programa; pesquisou-se a visão dos funcionários - gerentes, chefias, técnicos e nível operacional - em relação a implantação do PQT e QVT, apontando as principais dificuldades e limitações na implantação do programa para a melhoria da qualidade de vida (QV) dos funcionários; e finalmente, com base no estudo realizado, sugeriram-se aspectos que a organização poderia modificar, para melhorar a QV dos funcionários da GERAD na DR/SC.

Inseridas num cenário cada vez mais competitivo, as organizações e, principalmente, as empresas públicas, têm cada vez mais a função de suprir as expectativas da sociedade e, para isso, devem estar voltadas para a valorização e o respeito do ser humano. Diante do exposto, a questão central deste trabalho é esta: como a introdução do programa de qualidade total afeta a qualidade de vida no trabalho em uma empresa pública prestadora de serviços?

\section{Referencial Teórico-Empírico do Estudo}

Na última década, com o advento da globalização, as empresas têm sido pressionadas por acirrada disputa de mercado. Neste contexto, uma organização deve ser compreendida como "unidade social artificialmente criada e estruturada, continuadamente alterada para se manter no tempo, e com a função de atingir metas específicas que satisfaçam as necessidades de seus participantes e da sociedade" (Etzioni, 1981, p. 07).

Segundo Garvin (1992, p. 25), neste momento, "pela primeira vez, altos executivos, em nível de presidência e alta diretoria, expressam interesse na qualidade, ligando-a com lucratividade, definindo-a do ponto de vista do cliente e requerendo sua inclusão no processo de planejamento estratégico".

Dentro desta filosofia de trabalho, durante a última década, empresas brasileiras e de todo o mundo passaram a introduzir, de forma mais acentuada, os sistemas participativos de gestão com o objetivo principal de aumentar a produtividade e apoiar os programas de qualidade, mas não visando realmente à participa- 
ção dos empregados, conforme se verifica nas pesquisas do NINEIT (Relatório CNPq, 1998).

Ressalta-se, porém, segundo Albuquerque e França (1998, p. 40) que "o ambiente empresarial brasileiro vem se tornando intensamente competitivo em virtude das profundas mudanças que vêm ocorrendo na economia mundial, nas relações sociais e políticas, na tecnologia, na organização produtiva, nas relações de trabalho e na própria inserção do elemento humano no tecido social e produtivo". Ainda segundo os autores, especificamente tratando-se do Brasil, "essas transformações assumiram expressão maior em conseqüência da abertura abrupta da economia, da implementação dos programas de estabilização monetária e das reformas constitucionais, visando à redução e à reorientação do papel do Estado na economia" (Albuquerque e França, 1998, p. 40).

Para fazer frente a esses desafios, na busca pela melhoria de processos, redução de custos e aumento da satisfação dos clientes, um número cada vez maior de empresas brasileiras implantam o chamado PQT. Entretanto, com tamanha importância que a questão da qualidade total vem assumindo dentro do ambiente de trabalho e no contexto empresarial, autores mais críticos questionam como estes programas tratam a questão do trabalho. Como Neves (1993, p. 276), por exemplo, cuja reflexão é no sentido de que "o trabalho não pode ser compreendido apenas sob a ótica do processo gestionário, e a empresa não pode estar desvinculada da sociedade. Pensar uma política de qualidade nas empresas implica pensar na qualidade de vida de seus trabalhadores, no efetivo exercício de seus direitos trabalhistas, consolidando cada vez mais as instituições da sociedade para afirmação do processo democrático na sociedade brasileira".

O PQT é uma técnica de administração aperfeiçoada no Japão, a partir de idéias americanas ali introduzidas logo após a Segunda Guerra Mundial. Garvin (1992) descreve o desenvolvimento da qualidade em quatro eras, divididas na fase da inspeção formal, do controle estatístico do processo, da garantia da qualidade e da gestão estratégica da qualidade. Não é intenção deste artigo aprofundar-se nas origens deste programa, mas verificar como a QT está afetando as relações de trabalho, e mais precisamente a QVT.

Para Campos (1989, p. 13) o programa de qualidade total "é baseado em elementos de várias fontes: emprega o método cartesiano, aproveita muito do trabalho de Taylor, utiliza o controle estatístico de processo, adota os conceitos sobre comportamento humano lançados por Maslow e aproveita todo o conhecimento ocidental sobre a qualidade, principalmente o trabalho de Juran". Percebe-se como este conceito revela a verdadeira origem da QT, com base nos programas tayloristas de racionalização e eficiência, no produtivismo, e considerando as bases behavioristas com o objetivo de manipulação dos trabalhadores. 
Por isso a qualidade total é entendida como "o controle exercido por todas as pessoas para a satisfação das necessidades de todas as pessoas" (Campos, 1992, p. 15). Este é um conceito muito amplo, vazio e pouco elucidativo, pois questiona-se quem são essas pessoas às quais o autor se refere. Com o passar do tempo, o discurso torna-se mais objetivo e menos evasivo, conceituando a qualidade como "um sistema de gerenciamento empresarial voltado para a satisfação das pessoas; não por extorsão, mas por métodos e técnicas que todos os funcionários devem aprender para o crescimento da empresa. Pessoas nesse caso quer dizer: clientes (mercado consumidor), empregados (mercado de trabalho), acionistas (mercado financeiro) e vizinhos (mercado amplo e sociedade)" (Campos, 1998, p. 07).

Pelos conceitos de qualidade apresentados, constata-se que este é um modelo de racionalização que visa em primeiro lugar, à máxima produtividade e a redução de custos, tentando, de todas as formas, voltar a empresa ao atendimento das reais necessidades dos seus clientes; entretanto a preocupação das empresas em relação ao seu micro e macro ambiente, onde o processo de melhoria contínua faz com que as pessoas deixem de ser meros empregados para assumirem um papel de colaboradores, demonstra que é necessário o envolvimento das pessoas para se alcançarem as metas do programa; contudo observa-se nos discursos funcionalistas e gerenciais que a preocupação das empresas com a introdução de novas técnicas de gestão e desenvolvimento constante do pessoal, tem por objetivo maior alcançar ganhos de produtividade, e somente em última instância melhorar o bemestar e as condições de trabalho das pessoas.

Neste contexto, em meio a tantos desafios, muitas empresas têm encontrado nos PQT uma saída para alcançar maior produtividade e competitividade; entretanto surge a pergunta: os programas de qualidade total, em contrapartida ao aumento de exigência sobre os funcionários, trazem benefícios para a melhoria da qualidade de vida das pessoas?

Essa questão é um tanto quanto polêmica e "se o discurso é carregado de referência à responsabilidade social da empresa, às noções de bem-estar e valorização do ser humano, à participação, à criatividade e à comunicação vertical ascendente, a verdade é que tal discurso se mostra ineficaz, quando, a nível prático, o que predomina são os preconceitos nas relações de poder, na efetividade das relações de trabalho" (Fernandes, 1988, p. 30).

Para reforçar estas idéias, é importante destacar que em pesquisa realizada em empresas catarinenses da indústria mecânica, Guimarães (1995) constatou o ceticismo do gerente de produção em uma das empresas pesquisadas "com relação aos resultados dos diversos programas de qualidade, iniciados na empresa e coordenados pelo Grupo de Qualidade, porque não ofereceram, objetivamente, nenhuma vantagem ao empregado. [...] Houve situações em que pôde-se perceber um 
imenso distanciamento entre o discurso gerencial e as condições objetivas de trabalho".

Desta forma, nota-se que, apesar de que o discurso da qualidade total enfatiza expressões como satisfação, participação e comprometimento de ambas as partes, no dia-a-dia das empresas o que se verifica é simplesmente o aumento da pressão por resultados sobre os funcionários, pois estes devem produzir mais e melhor, dentro de padrões especificados pela direção. Desta maneira, principalmente pela característica de implantação, efeito chuveiro (top-down) deste modelo, surgem questionamentos sobre até que ponto ele pode ser considerado participativo (Roesch e Antunes, 1995).

Diante das questões colocadas, pode-se perceber que a gestão da qualidade traz consigo um processo de transformação cultural, que não é instantâneo, mas um processo gradativo em que o investimento da empresa deve ser concentrado nas pessoas, na tentativa de conscientização para a necessidade de mudança, tendo como finalidade última o envolvimento de todos os membros da organização na busca da qualidade.

No caso da ECT, que passa por um processo de reestruturação, redefinindo sua estrutura e sua filosofia de negócio, é necessário que se compreenda a transformação da função das pessoas neste processo. Muito mais importante do que a empresa ter um conceito ideológico de qualidade, é fundamental que se estabeleça uma efetiva política de valorização da participação das pessoas no PQT, bem como se faz necessário identificar que tipo de influência a introdução de tal programa exerce sobre elas. Questiona-se ainda, como a QVT pode ser afetada e auxiliar, de maneira mais democrática, a utilização da filosofia da qualidade.

Portanto entende-se que a qualidade de vida deve ser uma preocupação compreendida e incorporada ao discurso daqueles que buscam a qualidade total. Neste momento, cabe registrar que a conceituação de QVT é bastante ampla e proporciona várias interpretações. Neste trabalho, busca-se uma conceituação de QVT que parte da crítica dos ensinamentos de Guimarães (1998, p. 79), quando considera que "uma interpretação restrita trata a QVT apenas como um método de assepsia ambiental (melhorias somente no ambiente físico), ou de engenharia de segurança (redução de riscos). Também limitadas são as interpretações que se restringem aos aspectos ergonômicos do trabalho, ou exclusivamente correlatos à saúde física e ocupacional dos empregados, ou ainda, aos aspectos psicológicos/ comportamentais do trabalho (exploração do potencial criativo do empregado, perspectivas de crescimento profissional, informações sobre o seu desempenho, incentivos salariais)".

Desta forma, não somente os aspectos do ambiente físico ou questões relaciona- 
das à remuneração e segurança no trabalho devem fazer parte das práticas da QT e QVT, mas também o de proporcionar às pessoas espaço para exporem suas idéias e oportunidades de participarem nas decisões, ampliando o horizonte de democracia na empresa.

Com isso, neste trabalho, ao falar em QVT, fala-se em democratização do ambiente de trabalho e satisfação do trabalhador, indo de encontro à "busca para humanizar as relações de trabalho na organização, mantendo uma relação estreita com a produtividade e principalmente com a satisfação do trabalhador no seu ambiente de trabalho. Constitui-se, ainda, em condição de vida no trabalho, associada ao bem-estar, à saúde e à segurança do trabalhador" (Búrigo, 1997, p. 30).

Dentro desta concepção, Guimarães (1995) sugere uma concepção ampla de QVT "relacionada com 'qualidade de vida' em geral, o que inclui a conquista da cidadania por parte do trabalhador, mantendo 'uma relação direta e atávica com a democratização industrial', enquanto compartilhamento do poder de decisão entre gerências e trabalhadores, assumindo-se uma forma de participação plena em todos os níveis decisórios".

Em síntese, corroboram-se as idéias de Guimarães (1995) que reconhece que a QVT está relacionada com o projeto ergonômico dos postos de trabalho, referente à organização, limpeza, segurança, conforto ambiental, controle da poluição física e acústica, controle da temperatura e da luminosidade, mas não se restringe exclusivamente às condições físicas, pois inclui também itens como oferecimento de benefícios sociais e, o mais importante, as relações de trabalho e o ambiente social, onde é proporcionado ao trabalhador o seu desenvolvimento como pessoa capaz de refletir e de produzir idéias.

\section{Metodologia da Pesquisa}

Este estudo caracteriza-se como teórico-empírico, em que o processo de pesquisa se iniciou por meio de um estudo exploratório do tema. Posteriormente, assumiu-se um delineamento descritivo, pois os objetivos propostos foram alcançados por meio da descrição e análise da opinião das pessoas em relação ao PQT e sobre sua influência na QVT.

O trabalho teve abordagem predominantemente qualitativa, justificada principalmente pela natureza e complexidade do tema/problema, pelo nível de profundidade requerido pelo estudo e pelo tipo de observações, informações e análises necessárias para responder à questão central de pesquisa (Chizzotti, 1991). 
O procedimento metodológico privilegiou o estudo de caso, aplicado na GERAD/ $\mathrm{DR} / \mathrm{SC}$ da ECT. Dentro desta abordagem predominantemente qualitativa, a presente pesquisa teve uma perspectiva longitudinal: na GERAD avaliaram-se os aspectos da QVT antes e depois da introdução do PQT, e não somente em determinado momento do tempo. Em função da opção por uma unidade específica da organização para a aplicação da pesquisa, realizou-se também um corte seccional.

Respaldado em Triviños (1987), pelas características que apresenta, o estudo de caso pode ser tipificado como histórico-organizacional, pois o estudo recai sobre uma instituição; também é de tipo observacional, pois uma parte da coleta de dados foi realizada por meio da observação participante; comporta ainda a análise situacional, pois se refere a eventos específicos da realidade da organização.

Os dados foram coletados em fontes primárias e secundárias. A coleta de dados primários realizou-se em duas etapas. Na primeira, para levantar o perfil dos funcionários da GERAD, foram coletados dados via consulta documental e contato pessoal. Numa segunda etapa, os dados primários foram coletados via observação direta e pela aplicação de entrevistas semi-estruturadas. As entrevistas foram aplicadas numa amostra, em que os indivíduos selecionados representam um modelo reduzido da população total, na qual os diferentes grupos sociais da área pesquisada se encontram representados. Neste trabalho, também foi utilizado o levantamento em fontes secundárias, tais como pesquisa bibliográfica, pesquisa documental e pesquisa telematizada (Vergara, 1997).

Os elementos da amostra foram escolhidos em função de critérios qualitativos que nada têm de probabilísticos e não constituem, de modo algum, uma amostra representativa no sentido estatístico. Os critérios de seleção da amostra foram: o cargo do funcionário, sua lotação, a escolaridade, o tempo de serviço, a experiência de trabalho com mais de dois anos em outra empresa, a idade e o sexo. Coerentemente com a abordagem qualitativa (Michelat, 1987), procurou-se escolher os indivíduos que representassem as mais diversas categorias, constituindo, desta maneira, uma amostra heterogênea e bastante representativa da realidade total da empresa.

Com o objetivo de avaliar o modelo de Walton de QVT, utilizou-se como instrumento de coleta de dados um questionário semi-estruturado, aplicado numa amostra constituída por um total de 14 funcionários da GERAD. Além dos funcionários da GERAD, foram entrevistados um representante sindical e o gerente de assessoria de planejamento e qualidade (APLAQ), responsável pela implantação do PQT na DR/SC.

As entrevistas foram gravadas e transcritas, recebendo tratamento qualitativo na sua análise. Para tanto, conforme sugere Michelat (1987), adotou-se o proce- 
dimento de leitura vertical de cada questão, que serviu para guardar a lógica de cada entrevista, ao passo que o procedimento de leitura horizontal serviu para estabelecer uma relação com as outras entrevistas.

Para ampliar o horizonte de análise das informações e para verificar a existência de depoimentos conflitantes entre a Gerência de Planejamento e Qualidade, Gerência de Administração, funcionários e o representante sindical, utilizou-se a técnica de triangulação dos dados.

\section{Modelo de Avaliação da Qualidade de Vida no Trabalho}

Após a análise comparativa de diversos modelos de avaliação da QVT, optouse pela utilização do modelo de Walton (apud Vieira, 1973) pelo fato de ele ser considerado na literatura corrente como o mais amplo, contemplando processos de diagnóstico de QVT, levando em conta fatores intra e extra-organização, como se pode observar no Quadro 1, apresentado na seqüência.

\section{Caracterização da Organização Pesquisada}

A Empresa Brasileira de Correios e Telégrafos é uma empresa que atende às necessidades de comunicação postal e telemática de consumidores e empresas de todo o Brasil. Por isso representa papel importante na comunicação dentro do contexto de desenvolvimento do país, visto que o Brasil é um país de comércio ativo, que se desenvolve industrialmente, e necessita de meios de comunicação eficientes, que sirvam como elo de ligação entre as diversas empresas atuantes no mercado e seus clientes. A ECT é também importante agente de ação social do Governo, estando presente em praticamente todos os municípios brasileiros, sendo muitas vezes o único ponto de representação governamental em certas localidades.

Hoje a ECT, segundo dados fornecidos pela empresa, tem em seu quadro funcional aproximadamente 80.000 funcionários, distribuídos pelas 23 diretorias regionais (DR's) espalhadas em todo o território nacional. A Diretoria Regional de Santa Catarina (DR/SC) tem sede em Florianópolis, SC; é responsável pela execução dos serviços referentes a empresa no Estado. A estrutura da DR/SC é constituída por cerca de 2.200 empregados mais os estagiários e menores carentes. 


\section{Quadro 1: Modelo de Walton para Aferição da Qualidade de Vida no Trabalho}

\begin{tabular}{|c|c|}
\hline CRITÉRIOS & INDICADORES DE Q.V.T. \\
\hline 1. Compensação justa e adequada & $\begin{array}{l}\text { Renda adequada ao trabalho } \\
\text { Eqüidade interna } \\
\text { Eqüidade externa }\end{array}$ \\
\hline 2. Condições de trabalho & $\begin{array}{l}\text { Jornada de trabalho razoável } \\
\text { Ambiente fisico seguro e saudável }\end{array}$ \\
\hline $\begin{array}{l}\text { 3. Uso e desenvolvimento de } \\
\text { capacidades }\end{array}$ & $\begin{array}{l}\text { Autonomia } \\
\text { Significado da tarefa } \\
\text { Identidade da tarefa } \\
\text { Variedade de habilidade } \\
\text { Retroinformação } \\
\end{array}$ \\
\hline $\begin{array}{l}\text { 4. Oportunidade de crescimento e } \\
\text { segurança }\end{array}$ & $\begin{array}{l}\text { Possibilidade de carreira } \\
\text { Crescimento pessoal } \\
\text { Segurança no emprego }\end{array}$ \\
\hline 5. Integração social na empresa & $\begin{array}{l}\text { Igualdade de oportunidades } \\
\text { Relacionamento } \\
\text { Senso comunitário }\end{array}$ \\
\hline 6. Constitucionalismo & $\begin{array}{l}\text { Respeito às leis e direitos trabalhistas } \\
\text { Privacidade pessoal } \\
\text { Liberdade de expressão } \\
\text { Normas e rotinas }\end{array}$ \\
\hline $\begin{array}{l}\text { 7. O trabalho e o espaço total da } \\
\text { vida }\end{array}$ & Papel balanceado do trabalho \\
\hline $\begin{array}{l}\text { 8. Relevância social da vida no } \\
\text { trabalho }\end{array}$ & $\begin{array}{l}\text { Imagem da empresa } \\
\text { Responsabilidade social pelos } \\
\text { empregados } \\
\text { Responsabilidade pelos produtos e } \\
\text { serviços }\end{array}$ \\
\hline
\end{tabular}

Fonte: Walton (1973).

\section{A Qualidade Total na Empresa Brasileira de Correios e Telégrafos}

A história da QT na ECT/DR/SC começou em junho de 1993 com a criação do Comitê da Qualidade. O programa foi instituído na empresa sob a coordenação da Assessoria da Qualidade (ASQUA), que "tem como principal atividade fazer com que a cultura da QT seja cada vez mais incorporada ao dia-a-dia da ECT" (Correios, 1997, p. 17). 
O primeiro passo foi o comprometimento da alta administração e de todos os membros do corpo gerencial. A partir de então, iniciou-se o processo de sensibilização de todos os colaboradores para a necessidade de implementação de um amplo programa de qualidade, com o intuito de abranger todos os níveis e atividades da empresa. Foi implementado também o programa de capacitação de lideranças para a qualidade e produtividade, com o objetivo de recuperar a cultura da aferição da produtividade; portanto a filosofia da ECT é a de que todos os colaboradores sejam "engajados no processo de implantação e informados da política, das diretrizes e do plano básico de atividades a serem implementadas com vistas a tornar a Qualidade Total um estilo de gestão integrado à administração da Empresa" (Correios, 1997, p. 18).

Desta forma, na visão dos gestores da ECT, para que o programa obtenha êxito "é necessária uma base cultural bem estabelecida, com foco no atendimento das expectativas dos clientes e do mercado, fundamentada no compromisso e na participação de todos os ecetistas" (Correios, 1997, p. 19).

\section{A Qualidade Total na Diretoria Regional de Santa Catarina}

A Assessoria de Planejamento e Qualidade (APLAQ) é o órgão responsável pela coordenação do $\mathrm{PQT}$ na $\mathrm{DR} / \mathrm{SC}$, desde quando a direção da empresa se decidiu pela implantação do programa. Segundo o gerente da APLAQ, o processo de introdução do PQT na ECT/DR/SC começou pela preparação das pessoas em programas de motivação para a qualidade, seguidos de treinamento das gerências e chefias, com ênfase nas ferramentas e instrumentos da QT, começando pelo $5 \mathrm{~S}$.

A DR/SC sempre se preocupou em obter os melhores índices de resultados do Brasil, e com a implantação do programa "as pessoas começaram a trabalhar preocupadas com o cliente. Hoje, as pessoas tem uma noção muito clara de que você precisa satisfazer o cliente, quer seja interno ou externo. Você tem de apresentar resultados, ser competitivo". Para tanto, na opinião do gerente da APLAQ, para que a introdução do PQT obtenha sucesso é fundamental uma decisão firme da direção e participação efetiva das gerências para que a qualidade realmente se torne uma realidade na empresa. Com isso, os resultados do PQT já podem ser percebidos, pois "com os treinamentos realizados, o cliente passou a ser o foco dos esforços. [...] O ambiente de trabalho melhorou em termos de lay-out, fluxo, ergonomia, e isso com certeza trouxe mais satisfação para os colaboradores" (gerente da qualidade). 


\section{GerênCia de Administraçāo - Gerad}

A Gerência de Administração (GERAD) foi a área selecionada para servir como objeto deste estudo. A área é responsável pela contratação e administração de suprimentos e materiais para toda a DR/SC. Desta forma, a GERAD desempenha papel de fundamental importância dentro da $\mathrm{DR} / \mathrm{SC}$, pois o trabalho de todas as unidades e agências do Estado dependem do bom andamento do serviço na área. Essa responsabilidade é sentida pelos funcionários que têm muito orgulho de trabalhar na área de patrimônio e, mais, de estarem fazendo parte de uma empresa como a ECT que, segundo eles, presta um serviço de vital importância para toda a sociedade brasileira.

\section{O Sindicato da Empresa Brasileira de Correios e Telégrafos (SINTECT) diante do Programa de Qualidade Total}

Se, por um lado, os PQT ajudam as empresas a obterem melhores padrões de qualidade, por outro "acaba-se esquecendo as pessoas, o ser humano que está por trás da coisa" (representante do sindicato).

$\mathrm{Na}$ visão do representante sindical, estes programas apresentam algumas falhas, tais como a demissão de funcionários mais velhos que não têm o mesmo rendimento dos mais novos, por meio do programa de demissão voluntária e funcionários mais antigos, que apresentam problemas de saúde, ficam descartados dentro do programa. Ele continua, destacando que é "importante você ter um programa que incentive o cara, que faça as coisas melhorarem dentro do setor de trabalho, que faça você ter um rendimento melhor. Isso é importante [...] mas nos Correios a gente observa que o funcionário em si não se motiva por esses programas. Não há preocupação do funcionário, do peão, lá dentro do setor de trabalho com essa questão da QT. Ele observa isso como uma forma de ter mais trabalho". Outra falha apontada está relacionada com a falta de discussão e preparação dos funcionários em relação à mudança. Na sua opinião, a comunicação com o funcionário é feita de forma incorreta, deixando-o sem entender direito o que é o PQT. Isso torna-se mais complicado, porque o nível de escolaridade na ECT, apesar de estar melhorando nos últimos anos, ainda é muito baixo: do total do pessoal permanente em 1997, aproximadamente $87 \%$ é de nível básico, $10 \%$ de nível médio e somente $3 \%$ possui nível superior.

Entretanto o representante sindical tece críticas ao sindicato: "muitas vezes o 
sindicato critica os PQT, mas não se preocupa em tomar mais conhecimento do assunto". Para ele, QT "é tentar fazer as coisas da melhor forma possível, da maneira mais racional, da maneira mais exeqüível possível. Qualidade tem que estar inserida dentro de cada pessoa, não como uma obrigação, mas como uma concepção de vida".

Mesmo apresentando falhas, na opinião do representante sindical, já se pode sentir alguns resultados positivos com a introdução do PQT. Segundo ele, houve melhora na produção e no rendimento dos funcionários, mas isso deve-se ao fato de a empresa ter preparado as chefias para fazer uma cobrança mais direta. A empresa também preocupou-se em dar melhores condições físicas de trabalho, investindo em móveis e equipamentos. Em relação às questões de produtividade e remuneração dos funcionários, o sindicato faz algumas críticas aos PQT dizendo que se tenta relacionar remuneração ao desempenho dos funcionários, "e isso é muitas vezes um tanto quanto complicado, porque não se respeita a individualidade das pessoas. Até por uma questão natural, eu não tenho a obrigação de ter o mesmo rendimento que outra pessoa".

\section{INTERPRETAÇÕES DE QuALIDADE TOTAL}

Buscou-se junto aos entrevistados o significado de qualidade total. Nas declarações, percebeu-se uma tendência em associar QT à satisfação do cliente, tanto interno quanto externo, e em relação à qualidade dos produtos e serviços prestados; entretanto outras conotações também foram apresentadas, enquadrando a qualidade como ferramenta competitiva da empresa no mercado. Os entrevistados também enquadram a qualidade como conformação a uma norma ou padrão, estabelecido pela empresa, na tentativa de reduzir ao máximo os erros e defeitos ao longo do processo, para incrementar a qualidade dos produtos e serviços para o cliente.

Por outro lado, observou-se que QT pode estar associada a uma condição de trabalho melhor, conforme se percebe na declaração de um funcionário: "De uma forma geral é uma melhor condição de trabalho para a pessoa, que o cara tenha um bom ambiente de trabalho, tenha equipamentos à disposição para melhorar 0 trabalho dele, tenha material disponível”.

O conceito de QT está sendo utilizado de forma ampla; nele se enquadram diversas variáveis. Destaca-se que, na linha de condução desta pesquisa, a QT impregna-se de visão mais humanística, associada à QV e QVT, onde a satisfação 
das pessoas deve ter um lugar saliente e não somente como conformação a uma norma, redução de erros e defeitos, alcance de metas ou maximização de lucros para a empresa.

No caso da ECT, 5 entrevistados revelaram que tiveram boa aceitação quanto à introdução do PQT, enquanto outros 5 resistiram em aceitar a mudança. Um dos entrevistados tem uma opinião mais enérgica, quando classifica o processo de introdução do PQT como traumático. Surpreendentemente 3 entrevistados declararam não ter nenhum conhecimento do processo de introdução do PQT na empresa, justificando que participaram somente de uma palestra ou que sabem alguma coisa somente pelos colegas.

Destaca-se este ponto, pois ficou evidente, nos relatos, que a introdução do PQT foi acompanhada de resistência, principalmente pelo desconhecimento dos funcionários sobre os objetivos do programa. A pouca divulgação do programa é considerada como um dos elementos que causou esta resistência. Quando se questionou o envolvimento dos funcionários com o programa, houve nítida tendência dos entrevistados em dizer que estão envolvidos em bem executar suas tarefas: atendem bem aos clientes e participam do programa $5 \mathrm{~S}$, mantendo o ambiente limpo e organizado.

Outra preocupação dos funcionários se referia à adequação ao novo sistema, visando garantir o emprego. Esta afirmação pode ser percebida na declaração de um entrevistado, quando diz que "somos empregados da empresa, somos colaboradores, a gente têm de se adequar a esse novo sistema e fazer o melhor possível para não perder o emprego mais tarde". Vê-se que, apesar de existir preocupação em relação à privatização e ao desemprego, não é comentada explicitamente; ele assume uma estratégia inteligente de aceitar o novo sistema adotado pela empresa.

Em relação às inovações introduzidas com o PQT, na opinião dos entrevistados, as principais foram a racionalização de processos e do material, da mesma forma que é proposto pelo sistema taylorista/fordista; o programa $5 \mathrm{~S}$ que, por meio do senso de utilização, ordenação, limpeza, saúde e autodisciplina, tem como principal meta melhorar as condições do ambiente de trabalho; melhoria nas relações de trabalho; investimento em tecnologia e incentivos para aperfeiçoamento; mudanças na estrutura da empresa; a implantação do gerenciamento do desempenho, com a finalidade de aumentar o controle sobre o desempenho dos funcionários e, de certa forma, proporcionar também um feed-back para eles sobre seu trabalho. 


\section{InTERPRetaÇÕes de Qualidade de Vida no Trabalho}

Para o gerente da APLAQ, "QVT é gerar condições adequadas às pessoas, dar os meios para elas sentirem satisfação de vir trabalhar. É as pessoas se sentirem bem no ambiente de trabalho, se sentir útil, respeitado, valorizado e reconhecido".

Por sua vez, o gerente de administração interpreta QVT como uma forma de a "pessoa se sentir bem no ambiente de trabalho, que o trabalho não seja uma carga negativa que ela tenha que carregar, seja uma forma de realização pessoal, que ela faça amizades, tenha bom relacionamento com seus colegas e que ela desenvolva todas as suas habilidades".

Um dos chefes de seção conseguiu acrescentar novos elementos; segundo ele, "QVT é o relacionamento entre os colegas, entre chefes e subordinados. A preocupação dos dirigentes com relação à família do servidor e que o servidor se sinta feliz, às vezes não no trabalho, na função que ele exerce diretamente, mas de forma geral". O diferencial de sua análise está no fato de que o entrevistado consegue extrapolar o conceito de QVT para a QV em geral, quando relaciona QVT aos aspectos da família, constituindo, sem dúvida, uma interpretação mais ampliada de QVT.

Para o representante do sindicato, QVT é "ter condições de realizar o trabalho e sair satisfeito em cumprir com a jornada de trabalho. Diferente de sair do setor de trabalho cansado, não ter o material necessário para desempenhar suas funções. QVT é você sair do serviço como você entrou, se você entrou bem, tem que sair bem". Deve-se enfatizar, quanto à interpretação do representante sindical, que não destaca aspectos como democratização e a participação dos funcionários nas decisões, não apresentando uma interpretação política sobre o tema, o que era de se esperar.

De maneira geral, os funcionários da GERAD entendem QVT como ter um bom ambiente de trabalho (6), incluindo-se as condições físicas e relacionamento interpessoal, ter boa remuneração (5), gostar do que faz (3), trabalhar em boas condições físicas e emocionais (3), ter satisfação de trabalhar (2), não receber pressão desnecessária dos superiores (1) e procurar o bem comum (1).

Quando foi solicitado aos entrevistados que relacionassem QVT e QV, eles responderam que essas duas categorias estão estritamente relacionadas. Salientam os entrevistados que essas duas categorias não podem estar dissociadas, porque, para ter boa QVT, é fundamental que a empresa proporcione os meios necessários para que a pessoa tenha uma boa QV de modo geral. Na verdade, acredita-se que estas duas categorias estão intimamente ligadas, porque as pessoas passam apro- 
ximadamente um terço da vida no trabalho, e isto é muito representativo no contexto geral de sua existência.

Como decorrência da própria interpretação, a maioria dos entrevistados entende que os principais indicadores de QVT na empresa são os aspectos de bom relacionamento interpessoal, bom ambiente de trabalho e boa remuneração. Foram citados também, com menor ênfase, a satisfação no trabalho, a segurança no emprego, o reconhecimento e a motivação dos funcionários. Dois entrevistados entendem que a QVT também está relacionada indiretamente com a produtividade, com o bom atendimento aos clientes e com a responsabilidade perante a empresa.

\section{Resultados da Avaliação do Modelo de Walton de Qualidade de Vida No TrabalHo}

Os resultados encontrados em relação ao critério de compensação justa e adequada demonstram alto grau de insatisfação quanto à remuneração e à eqüidade interna, e muito desconhecimento quanto à eqüidade externa.

Em relação ao critério de condições de trabalho, os entrevistados demonstram insatisfação com a jornada de trabalho; entretanto foi percebido alto grau de satisfação com o ambiente físico de trabalho, apesar de a maioria inicialmente ter afirmado que as condições físicas são satisfatórias.

Neste critério de uso e desenvolvimento de capacidades, o maior nível de satisfação ocorreu no significado e na identidade da tarefa; no indicador de autonomia e de retroinformação, os entrevistados apresentaram nível adequado de satisfação. Neste critério, o menor nível de satisfação foi encontrado no indicador uso de habilidades múltiplas.

No critério oportunidade de crescimento e segurança, o indicador crescimento pessoal apresenta o maior grau de satisfação. A possibilidade de carreira é considerada com nível satisfatório; a segurança no emprego demonstra o menor nível de satisfação entre os entrevistados.

O resultado encontrado no critério integração social na empresa aponta alto grau de satisfação nos indicadores de relacionamento e senso comunitário; entretanto apresenta baixo nível de satisfação quanto ao indicador de igualdade na distribuição de oportunidades.

Quanto ao critério constitucionalismo, os resultados, de maneira geral, apon- 
tam um bom nível de satisfação em relação aos indicadores de respeito às leis e direitos trabalhistas, normas e rotinas e, principalmente, quanto à liberdade de expressão, apesar da pressão negativa exercida sobre a questão da sindicalização. Entretanto, o nível de satisfação em relação ao indicador de privacidade pessoal apresenta-se insatisfatório.

No critério em que os entrevistados foram questionados em relação ao espaço total que o trabalho representa em sua vida particular, com base nos resultados alcançados, constata-se um nível satisfatório em relação ao papel balanceado do trabalho na vida pessoal dos entrevistados.

Finalmente, no critério de relevância social da vida no trabalho, os resultados encontrados demonstram bom nível de satisfação quanto à imagem da empresa, responsabilidade da empresa por produtos e serviços, e nível insatisfatório quanto à responsabilidade social da empresa em relação aos empregados, pois de modo geral há um sentimento de orgulho por trabalhar numa empresa como a ECT, em parte pelo prestígio e imagem institucional favorável junto à sociedade.

\section{Relação entre a Introdução do Programa de Qualidade Total e Qualidade de Vida no Trabalho}

A quase totalidade dos entrevistados reconhece que houve melhorias na QVT a partir da introdução do PQT e que os principais avanços estão relacionados à preocupação da direção com a melhoria das condições físicas do ambiente de trabalho (apontada por 10 entrevistados), por meio do programa $5 \mathrm{~S}$. Em menor escala, foram citadas também uma maior preocupação da empresa quanto aos aspectos relacionados à saúde dos funcionários, que antes não existia; maior preocupação em prestar serviços de qualidade aos clientes internos e externos; maior preocupação com o lado humano dos funcionários; maior liberdade e mais reconhecimento. Também foi colocado que o nível de irregularidades na empresa diminuiu; mas, segundo os entrevistados, isso se deve ao fato de agora existir maior controle sobre os funcionários, tanto com relação ao seu desempenho, quanto aos gastos e despesas em geral.

Os resultados observados refletem uma realidade específica, de uma empresa pública prestadora de serviços, cuja análise corrobora, em parte, os resultados obtidos por Búrigo (1997), ao estudar o caso da UFSC e com alguns elementos comuns às pesquisas aplicadas no setor industrial (Guimarães, 1995; Vieira, 1996). 


\section{CONCLUSÓES}

O estudo da influência dos PQT na QVT na GERAD estabelece uma relação muito interessante de como a ECT vem buscando formas para melhorar sua eficiência e produtividade, e como tem encontrado alternativas para melhorar a QV de seus funcionários.

Na empresa, verificou-se que o PQT faz parte do Programa Nacional de Qualidade e Produtividade que, mediante a reavaliação de sua forma de gestão e relacionamento com empregados, se vem buscando na empresa: aumentar os níveis de produtividade, reduzindo custos e melhorando a qualidade na prestação dos serviços.

O que se verifica com este estudo é que o PQT deveria ser mais divulgado na empresa, principalmente em nível operacional, pois muitos funcionários demonstram desconhecimento em relação ao programa e aos conceitos implícitos nele; não houve efetiva preparação para a mudança e pouca discussão com eles sobre o assunto. Desta forma, acredita-se que o desconhecimento sobre o programa e sua metodologia de trabalho vem prejudicando os objetivos da direção, principalmente no que se refere ao comprometimento dos funcionários com as metas estabelecidas. Observou-se na empresa que as pessoas poderiam entender melhor a filosofia da QT e, desta forma, também contribuir de maneira mais efetiva com os objetivos do programa.

Neste caso, constatou-se que as principais dificuldades encontradas na implantação do PQT foram a falta de conceito próprio de qualidade, pouca preparação para a mudança, refletida em resistência, pouco conhecimento dos funcionários sobre QT, principalmente porque a empresa falhou na discussão e divulgação do programa em escalões mais baixos. Merece destaque a necessidade de adequação dos instrumentos e ferramentas da QT à realidade cultural da empresa, pois se deve respeitar as características próprias da ECT, que é empresa pública prestadora de serviços. Desta forma, entende-se que a filosofia da QT pode melhorar a QVT, desde que não seja utilizada somente para ganhos de produtividade, ou importada como pacote milagroso, coisa que muitas empresas estão fazendo atualmente, limitando o sucesso do programa como um todo.

Precisamente no caso da empresa, entende-se que o interesse deve ser concentrado mais na qualidade dos serviços prestados e na QVT de seus funcionários, ao invés da preocupação recair tanto no controle direto e vigilância excessiva sobre os funcionários, o que está restringindo a liberdade e gerando-se pressão desnecessária sobre eles. 
A política de treinamento precisa ser reavaliada, pois o programa de treinamento está sendo muito direcionado a gerências e chefias, quando deveria ser dada mais oportunidade para as pessoas situadas no nível mais baixo da pirâmide hierárquica, que geralmente são as pessoas que exigem maior preparação para entender as ferramentas e objetivos da qualidade.

$\mathrm{Na}$ ECT, os resultados demonstram que QT está associada a fatores como satisfação em trabalhar, reconhecimento, satisfação dos clientes internos e externos, alcance de metas e padrões estabelecidos, eliminação de erros e desperdícios e melhores condições de trabalho. A introdução do PQT na empresa deu-se de forma impositiva, fazendo surgir certa resistência dos funcionários no início; entretanto, aos poucos, estes se familiarizaram com o programa, contribuindo para o seu bom desenvolvimento. Nesse aspecto corroboram-se os resultados de outros estudos teórico-empíricos sobre o tema (Roesch e Antunes, 1995; Vieira, 1996; Búrigo, 1997).

Com relação às inovações, verificou-se que as principais introduzidas na empresa com o PQT foram a racionalização de processos e de material, o programa $5 \mathrm{~S}$, a melhoria nas relações de trabalho, o investimento em tecnologia, a implantação do gerenciamento do desempenho e incentivos para aperfeiçoamento, principalmente em nível gerencial e de chefia.

Neste trabalho, quando se fala em qualidade total, entende-se que necessariamente devem ser incluídos, na cultura da organização, fatores como democratização do ambiente de trabalho, mediante a abertura para o diálogo e espaço para expor idéias, participação nas decisões, maior senso comunitário, visão ecológi$\mathrm{ca}$, harmonia, estímulo à criatividade e ao desenvolvimento como profissional e como pessoa, endossando algumas tendências atuais de expansão do conceito de qualidade total (Albuquerque e França, 1998; Guimarães, 1998).

Desta forma, o conceito de qualidade deve ser ampliado, de modo que a QVT seja uma expansão natural do conceito de QT, sendo os programas introduzidos e gerenciados simultaneamente, pois o PQT só tem sentido se realmente proporcionar melhores condições de trabalho e satisfação para as pessoas, ou seja, melhorar suas condições de vida.

Neste sentido, entende-se que construir locais de trabalho saudáveis, onde exista participação das pessoas nas decisões que afetam suas vidas, contribui para a formação de uma sociedade mais justa e democrática; portanto precisamos criar novas formas de encarar o trabalho e o relacionamento interpessoal advindo dele, criando formas alternativas de organização que estimulem, de diferentes maneiras, o bom relacionamento das pessoas. 
Os programas de QVT devem ser encarados como alternativa para combinar ambientes participativos com um estilo de vida mais humano, integrando de forma harmônica o homem ao meio ambiente. O estilo de vida mais humano enquadra não somente aspectos físicos, mas também aspectos emocionais e espirituais (Búrigo, 1997).

Quanto às interpretações de QVT, as pessoas de modo geral, associaram-na a um melhor ambiente de trabalho, às condições físicas e de relacionamento, à remuneração, satisfação e identificação com o trabalho, como vem sendo apontado por outros estudos similares mencionados anteriormente.

Para sintetizar os resultados alcançados neste trabalho, apresenta-se uma avaliação final dos critérios de aferição da QVT do modelo de Walton, realizado na ECT/GERAD/DR/SC. Em relação aos critérios investigados, encontrou-se maior satisfação entre os indicadores de ambiente físico de trabalho, significado e identidade de tarefa, crescimento profissional, relacionamento interpessoal, senso comunitário, respeito às leis e direitos trabalhistas, normas e rotinas, liberdade de expressão, imagem da empresa e responsabilidade da empresa por produtos e serviços.

Encontrou-se nível satisfatório nos indicadores de autonomia, retroinformação, possibilidade de carreira e certo desconhecimento em relação à eqüidade externa. Por outro lado, foram observados níveis insatisfatórios quanto aos indicadores de remuneração, eqüidade interna, jornada de trabalho, uso de habilidades múltiplas, segurança no emprego, igualdade na distribuição de oportunidades, privacidade pessoal, papel balanceado da vida no trabalho e responsabilidade social da empresa em relação aos empregados, indicadores estes que devem conduzir a uma reavaliação do programa de qualidade total.

Para finalizar, entende-se que é importante deixar uma reflexão sobre a função da universidade como espaço que busca o desenvolvimento e a democratização de nossa sociedade, mediante a formação intelectual de seus estudantes, que deveriam assumir uma postura mais crítica diante dos modelos e modismos tão decantados e apregoados no meio acadêmico e empresarial como panacéias para a solução de todos os problemas institucionais, como o que acontece com os programas de qualidade total. 


\section{ReferénCias Bibliográficas}

\section{ALBUQUERQUE, L. G. DE;}

FRANÇA, A. C. L.

Estratégias de recursos humanos e gestão da qualidade de vida no trabalho : o stress e a expansão do conceito de qualidade total. Revista de Administração de Empresas, v. 33 , n. 2, p. 40-51, abr./ jun. 1998.

BÚRIGO, C. C. D.

Qualidade de vida no trabalho: dilemas e perspectivas. Florianópolis : Insular, 1997.

CAMPOS, V. F.

Gerência da qualidade total : estratégia para aumentar a competitividade da empresa brasileira. Belo Horizonte : Fundação Cristiano Ottoni, 1989.

TQC : controle da qualidade total (no estilo japonês). Rio de Janeiro : Bloch, 1992.

Gestão da qualidade : compromisso que gera satisfação e confiança. Correios Hoje, ano IV, n. 25, jan./fev. 1998.

ChizzotTI, A.

Pesquisa em ciências humanas e sociais. São Paulo : Cortez, 1991.

\section{CORREIOS HOJE.}

Comprometimento com a qualidade. ano 4, n. 21, mar./abr. 1997.

\section{ETZIONI, A.}

Sociologia industrial : o estudo das organizações econômicas. In: . (Org). Organizações complexas. São Paulo : Atlas, 1981.

FERNANDES, E. C.;

GUTIERREZ, L. H.

Qualidade de vida no trabalho (QVT) - uma experiência brasileira. Revista de Administração, p. 29-37, out./dez. 1988.

GARVIN, D. A.

Gerenciando a qualidade : a visão estratégica e competitiva. Rio de Janeiro : Qualitymark, 1992.

GUIMARÃES, V. N.

Novas tecnologias de produção de base microeletrônica e democracia industrial : estudo comparativo de casos na indústria mecânica de Santa Catarina. Florianópolis, 1995. Tese (Doutorado em Engenharia de Produção) Programa de Pós-Graduação em Engenharia de Produção, Universidade Federal de Santa Catarina. 
Qualidade de vida no trabalho e introdução de inovações tecnológicas : estudo comparativo de casos na indústria mecânica de Santa Catarina. Revista de Ciências da Administração, ano I, n. 0, ago. 1998.

LIMA, M. E. A.

Programas de qualidade total e seus impactos sobre a qualidade de vida no trabalho. Revista de Administração, v. 29, n. 4, p. 6472, out./dez. 1994.

MICHELAT, G.

Sobre a utilização da entrevista não-diretiva em sociologia. In: THIOLLENT, M. Crítica metodológica, investigação social e enquete operária. 5. ed. São Paulo : Polis, 1987.

NEVES, M. A.

Modernização industrial no Brasil : o surgimento de novos paradigmas na organização do trabalho. Educação \& Sociedade, n. 45, ago. 1993.

ROESCH, S. M. A.;

ANTUNES, E. DI D.

Gestão da qualidade total : lide- rança top-down versus gerenciamento participativo. Revista de Administração, v. 30, n. 3, p. 3849, jul./set. 1995.

TRIVIÑOS, A. N. S.

Introdução à pesquisa em ciências sociais : a pesquisa qualitativa em educação. São Paulo : Atlas, 1987.

VERGARA, S. C.

Projetos e relatórios de pesquisa em administração. São Paulo : Atlas, 1997.

VIEIRA, A.

A qualidade de vida no trabalho na gestão da qualidade total : um estudo de caso na Empresa Weg Motores em Jaraguá do Sul/SC. Florianópolis, 1996. Dissertação (Mestrado em Administração) Curso de Pós-Graduação em Administração, Universidade Federal de Santa Catarina.

WALTON, R. E.

Quality of working life : what is it? Sloan Management Review, v. 15, n. 1, p. 11-21, 1973. 